\title{
GEORREFERENCIAS DE LA PLANIMETRÍA E IMÁGENES DIGITALES EN ARQUEOLOGÍA: APLICACIÓN EN LA NECRÓPOLIS DE “LA CRUZ DEL NEGRO” (CARMONA, SEVILLA)
}

\section{GEO-REFERING OF PLANIMETRY AND DIGITAL IMAGES IN ARCHAEOLOGY. APPLICATION IN THE CRUZ DEL NEGRO (CARMONA, SEVILLA) NECROPOLIS}

\author{
por \\ PEDRO PÉREZ QUESADA y \\ FERNANDO AMORES CARREDANO
}

\begin{abstract}
RESUMEN Partiendo de los estudios realizados en la necrópolis tartésica de la "Cruz del Negro" se expone la aplicación a la investigación arqueológica de los principios teóricos básicos para georreferenciar elementos espaciales e imágenes digitales. Se muestran las correcciones geométricas efectuadas sobre el registro planimétrico del lugar desde las primeras intervenciones hasta las últimas prospecciones magnéticas.
\end{abstract}

\begin{abstract}
From the studies accomplished in the "Cruz del Negro" tartesian burial site, the application to the archaeological research of the basic theoretical principles necessary for geo-referencing spatial elements and digital images is exposed. The geometric corrections made on the plannimetric record of the site from the first interventions up to the last magnetic surveys are shown.
\end{abstract}

En la metodología arqueológica ha existido casi desde sus orígenes una preocupación por dos importantes aspectos, uno el objeto, el otro su localización; si bien en un primer momento el registro fiable, concreto y preciso de los objetos en sus coordenadas exactas de tiempo, espacio y estilo fue objetivo primordial de los primeros investigadores, hoy la renovación provocada por las "nuevas arqueologías" ha ampliado el objetivo de estudio a otros muchos items de diversa interpretación social, económica, ideológica... El avance en el registro de los contextos ha destacado la importancia del espacio como referente indiscutible para el tratamiento correcto de la información, de manera que la realización de una planimetría estratigráfica y secuencial se ha convertido en una de las preocupaciones básicas de cualquier intervención, entendiéndose como un elemento imprescindible para el análisis. No obstante, el contexto topográfico preciso en el que se enclava el sitio no siempre ha podido recibir la misma atención debido a razones diversas (insuficiencia resupuestaria, falta de tradición...). 
Esta frecuente carencia metodológica tiene varias consecuencias inmediatas como, son:

- El sitio carece de una geórreferenciación apropiada, lo cual complica el trabajo a la investigación territorial posterior y su inclusión veraz en cualquier inventario; lo que por demás tiene importantes consecuencias en cuanto a la protección efectiva del sitio.

- El cuadriculado de referencia para una campaña suele tener dificultades de relación en campañas sucesivas. El carácter científico y universal que debe regir la información arqueológica queda mermado para su amortización interpretativa futura.

Estos problemas son de más fácil solución en las intervenciones urbanas; ya que las referencias planimétricas de la misma ciudad circunscriben los resultados a parcelas acotadas catastralmente. En el ámbito rural, donde las referencias permanentes apenas existen, éstas han de ser establecidas mediante la colocación de puntos de control fijos; el problema se hace aún mayor cuando las estructuras son perecederas como es el caso de zanjas y fosas que pierden con facilidad sus perfiles y con ellos su utilidad como elementos de referencia.

La necrópolis tartésica de la Cruz del Negro (Carmona) podría tomarse como ejemplo de la evolución del valor asignado a la georreferenciación de sitios arqueológicos sometidos a reiteradas campañas de excavación ejecutadas por equipos y planteamientos diferentes. El lugar presenta la peculiaridad de que los únicos elementos que permanecen tras su excavación son las fosas empleadas en el ritual de enterramiento ya que están excavadas en la terraza cuaternaria de guijarros, de rápida degradación. La necesidad de dejar elementos de control planimétrico tras una campaña en un sitio de estas características parece a priori obvia, pero lo cierto es que no lo fue. Para poder enjuiciar en su justa medida este aspecto pasemos a recordar los hitos más signifiçativos de la intervención en el sitio.

El conocimiento de la necrópolis de la Cruz del Negro (Carmoná, Sevilla) dáta de fines del siglo pasado, cuando la construcción de la línea férrea Carmona-Guadajoz lo seccionó en dos mitades y puso al descubierto sus estructuras; de este hecho se derivaron diversas rebuscas y las excavaciones llevadas a cabo por J. Bonsor a partir de 1898 , de las que no tenemos mayor registro topográfico que su inclusión como un punto en el famoso y reducido mapa de localizaciones de Bonsor en Los Alcores (Bonsor 1997 [1899]: fig. 2) y los croquis de algunas tumbas excavadas (Maier 1992). Conservados sus restos por un siglo bajo un olivar, la memoria de su ubicación se perdió hasta que fue de nuevo localizada por Amores (1982: 109) siendo referenciada entonces como un punto en coordenadas Lambert. ${ }^{1}$ En el año 1989, el sitio fue objeto de una actuación ilegal de remociones de tierras que ocasionó la pérdida de buena parte de la necrópolis que determinó un expediente de intervención de úrgencia (Gil y otros 1991). A partir de 1993 se acometieron diversas excavaciones de acuerdo con un proyecto general de investigación-1993, 1995 y 1997-(Amores y otros 1997a, 1997b) y cuyo producto son los registros planimétricos que vamos a presentar.

La actuación de 1990 se estableció en un área de $2.500 \mathrm{~m}^{2}$ con una cuadrícula adeccuada a la utilizada en una prospección geofísica previa (llevada a cabo por Proarsa) con objeto de comprobar sus anomalías. Tras la verificación negativa de las anomalías, ya que tan sólo se detectó la línea internacional de Telefónica, la excavación convencional mantuvo el mismo cuadriculado. La planimetría de la intervención se realizó al modo tradicional solapando los resultados individuales de cada cuadrícula pero sin contextualización topográfica dẹl sitio y su entorno. ${ }^{2}$ Tratándose de una intervención de urgencia, parece ser que se entendió

1. Mapa Topográfico Nacional, escala de 1:50:000 edición militar 1918. Edición cartográfica de mayor calidad en la época.

2. Este modo de operar ha sido usual en España debido a las tradiciones metodológicas y a las envergaduras de intervención que ejecutaban gran parte de los equipos arqueológicos. Sondeos estratigráficos aislados de pequeñas dimensiones o áreas de pequeña extensión donde el contexto se resumía a la descripción gráfica de las estructuras en su cuadrícula respectiva y a la relación entre ellas. Aunque del texto publicado (Gil y otros 1991) se desprende que llevaron a cabo un levantamiento topográfico del sitio, la planimetría fruto de la intervención comprende únicamente las hojas 1:20 de las cuadrículas con el dibujo pormenorizado de los hallazgos y el ensamblaje de las mismas donde se resume la silueta de las estructuras funerarias. 
como finalista y no se fijaron puntos de control para posibles campañas posteriores o informes y actuaciones de protección, no obstante quedó patente que la porción afectada del sitio no estaba agotada.

La realización de una nueva campaña en 1993, en este caso encuadrada en un proyecto sistemático, tuvo que solventar el problema de la inexistencia de puntos de control. Se recuperó la cuadrícula de 1990 mediante topógrafos profesionales a partir de las alineaciones conservadas de testigos fijando sus vértices con barras de hierro y cemento (Amores y otros 1997b: fig. 1), con objeto de proseguir la exploración del sector amortizando los resultados anteriores. Aparte, se realizó un levantamiento topográfico a escala 1: 500 (a cargo de la empresa TecnoCart) mediante la restitución fotogramétrica del emplazamiento con la cual contextualizar la cuadrícula y las estructuras en el sitio y disponer de una herramienta de expresión y control gráficos (Amores y otros 1997a).

La siguiente campaña (1995) puso de manifiesto un hecho no previsto: la pérdida de todas las referencias fijas sobre el terreno por la acción expoliadora ${ }^{3}$; el recurso fue retomar de nuevo la dirección de un testigo de la campaña de 1990, esta vez con menos fiabilidad que en la campaña anterior. Sobre esta base se comenzaría a ordenar finalmente la planimetría de las sucesivas campañas realizadas. El procedimiento fue la captación directa de la planimetría arqueológica de 1990, 1993 y 1995 mediante tableta digitalizadora y su localización en el plano topográfico siguiendo las directrices marcadas por el cuadriculado de campo ${ }^{4}$.

Sin embargo, no sería hasta la ulterior campaña de 1997 cuando se plantearía la necesidad de georreferenciar el sitio en coordenadas U.T.M. para proceder a la liberación final del sector afectado del sitio. Como herramienta para sustentar una revisión final se encargó una prospección magnética a la empresa Terra Nova quien planteó su cuadrícula referenciándola a unos puntos de control fijos establecidos tras la campaña de 1995. A partir de lecturas continuas a equidistancias de medio metro se proporcionó una imagen de anomalías en el magnetismo terrestre, de diferente intensidad y distribuidas por todo el área registrada ${ }^{5}$.

La georreferenciación en coordenadas U.T.M. (de uso estandarizado para Andalucía) y el levantamiento topográfico del entorno se encargó de nuevo, en este caso a otra empresa de cartografía-Cartonme, Cartografía Numérica-, proporcionando además la posibilidad de reconstruir el proceso de destrucción del sitio a partir de pares estereoscópicos anteriores (1980) y posteriores (1995) al movimiento de tierras; en este último caso con la presencia en la imagen de las huellas de las excavaciones de 1990 y 1993. Se encargó asimismo una ampliación fotográfica del emplazamiento a partir de una de las tomás aéreas de 1995.

Con estas nuevas herramientas de trabajo se procedió a la ejecución de una intervención de urgencia en 1997 que liberara la porción del sitio afectada con las máximas garantías de fiabilidad. La permanencia esporádica de algunas puntillas de la intervención de 1993 y 1995, el "sembrado" de granalla metálica en 1990 para confundir a los expoliadores y los sucesivos errores acumulados en las "recuperaciones" de la cuadrícula base devenían en una inseguridad generalizada a la hora de interpretar correctamente las anomalías presentes en la planimetría geofísica. La encrucijada por tanto nos situaba en la necesidad de pasar de referenciaciones tradicionales, recuperaciones planimétricas parciales y acumulativas a sistemas de representación georreferenciados que permitían el control exhaustivo de una extensión con anomalías que habían de ser verificadas. Los márgenes de error eran importantes entre todas las planimetrías de tal modo que se recurrió a una revisión general aséptica y objetiva desde nuevas tecnologías sobre la que corregir las planimetrías acumuladas y proceder a la revisión de las anomalías cuya casuística hipotética incluía desde puntillas olvidadas y granalla hasta posibles estructuras funerarias.

El objetivo se resumía a la integración de la planimetría y de las anomalías en coordenadas reales para su comprobación. Además, se planteaba el objetivo de georreferenciar la imagen del sitio de manera que

3. La cercanía a la población determinó el robo sistemático de las barras o redondos de hierro.

4. Esta primera ordenación planimétrica estuvo a cargo de $\mathrm{M}^{\mathrm{a}} \mathrm{C}$. Rodríguez-Bobada.

5. Esta experiencia ha sido la de mayor intensidad realizada en un sitio arqueológico por la empresa debido al grado de precisión que se requería con objeto de controlar de modo sistemático la abundancia de estructuras funerarias y las posibles anomalías. 
proporcionase una referencia relativa de posibles errores de campo y en las orientaciones del cuadriculado de las sucesivas campañas.

\section{Discusión Teórica}

Para la transformación a coordenadas reales de estos tres registros (planimetría de campo, fotografía aérea e imagen de anomalías) hemos de partir de unas consideraciones teóricas previas que no sólo tienen que ver con su transformación geométrica sino también con su naturaleza física.

Sobre la naturaleza de los datos hay que distinguir unos aspectos fundamentales que determinarán el posterior tratamiento de los mismos y que están directamente relacionados con el proceso de captación.

Por una parte hay que señalar las características de las imágenes de que se dispone. Tanto una imagen aérea como una lectura del magnetismo terrestre obedecen al mismo principio físico cual es la detección de la energía electromagnética. Si bien el ojo humano sólo es capaz de detectar una pequeña franja del espectro electromagnético, en el caso de sensores ópticos y electrónicos la banda del espectro se amplía a longitudes de onda diferentes y la posibilidad de detectar características físicas soterradas se incrementa. Este principio, la discriminación de diferentes elementos mediante su registro energético, constituye por tanto el punto de partida de las imágenes resultantes que tendrán en cada uno de sus píxeles una constatación discreta de esa energía.

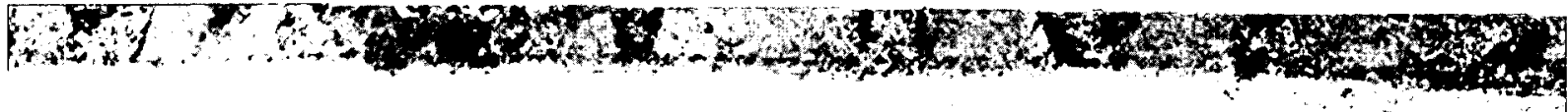

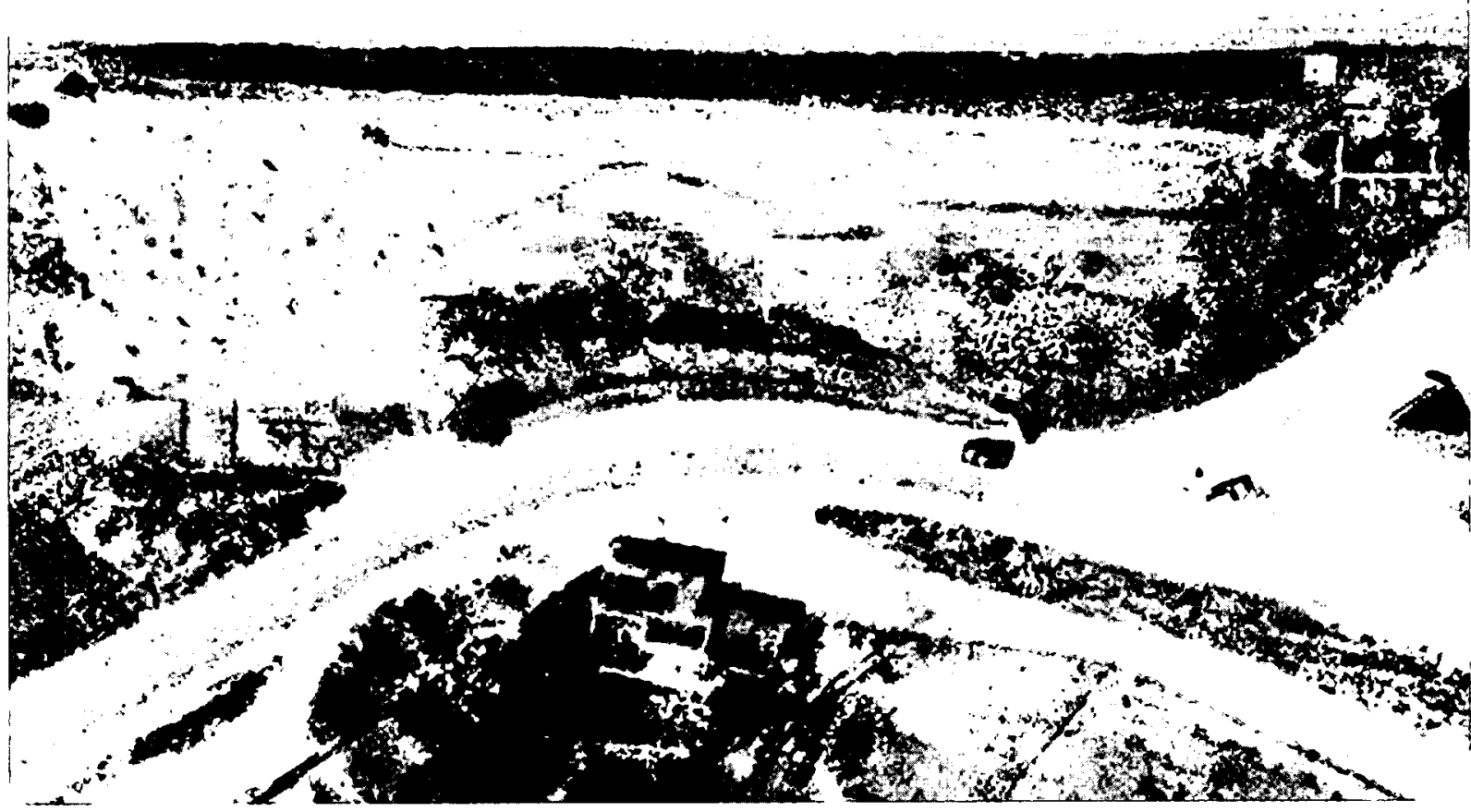

Lám. I.- Fotografía aérea de La Cruz del Negro. Escaneada a partir de ampliación fotográfica a escala 1:500 (Cartonme, septiembre, 1997) de un par estereoscópico original a 1:5.000. Zona 985 HMN (Instituto Cartográfico de Andalucía; Marzo, 1995). 
En el caso de fotografías, el funcionamiento consiste en la impresión de la energía reflejada por la superficie del objeto sobre emulsiones fotosensibles, con el apoyo de un sistema óptico que permite el control de las condiciones de exposición. El tipo de película empleado (en nuestro caso un film pancromático -blanco y negro- en el que se recoge todo el espectro visible sobre una sola emulsión), el ángulo de observación (perpendicular al terreno con un ángulo de visión inferior a los $5^{\circ}$ para nuestra toma), la distancia focal, la deformación cónica de los haces perspectivos, la altura o distancia de la superficie reflectante (altura del avión en fotogrametría aérea), las formas y composición química de ésta, la curvatura terrestre, el ángulo de la luz solar (energía fuente) y la situación atmosférica condicionarán en diverso grado el resultado fotográfico. Un último proceso de distorsión en la imagen resulta de su escaneado digital, que discretiza en píxeles los valores de las luminancias y cuyos principales defectos provienen de la adición o superposición de ruido (de patrón y aleatorio) y de las deformaciones propias del soporte en fotograma.

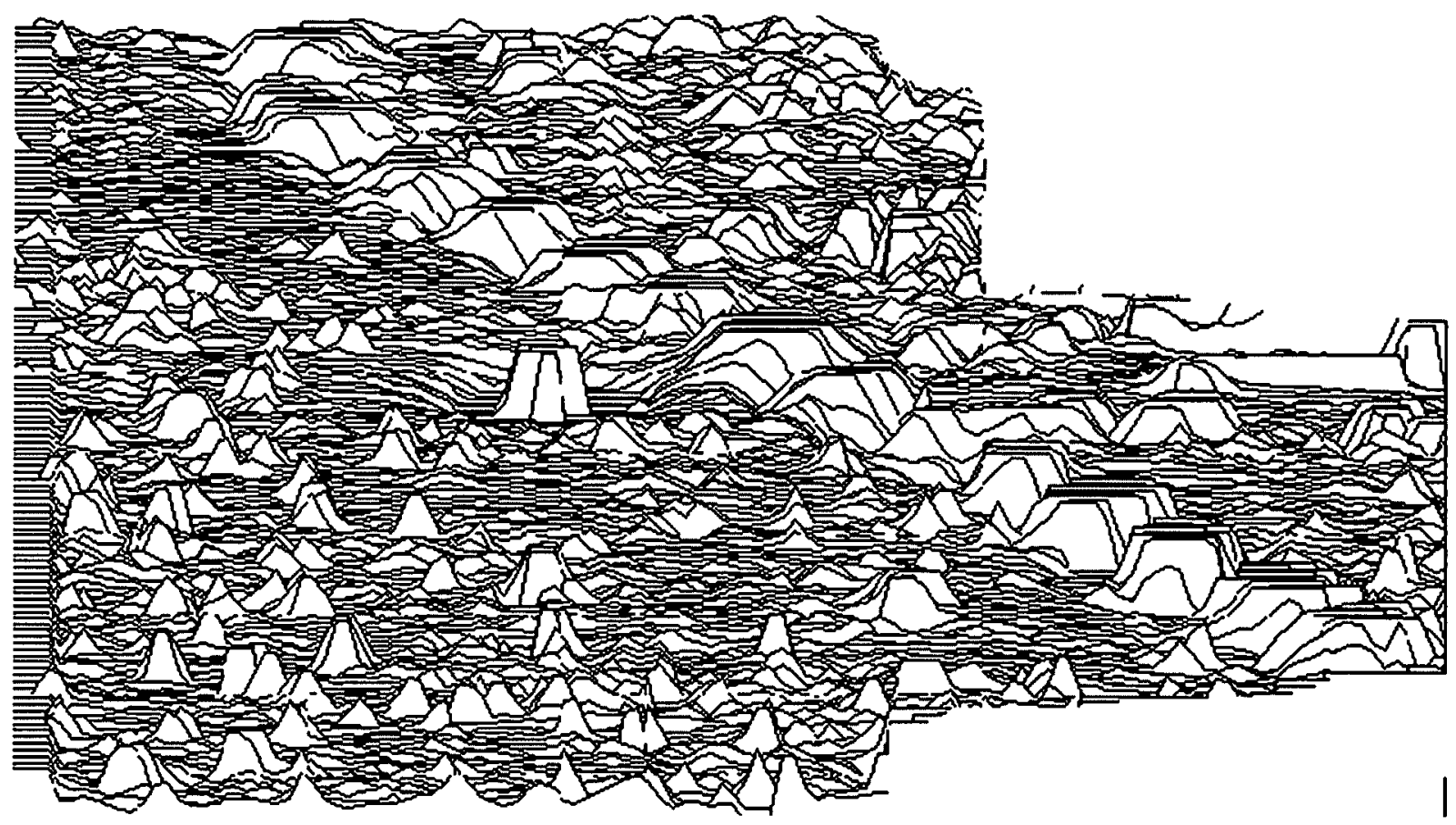

Fig 1.- Gráfico tridimensional de alteraciones magnéticas registradas por pasadas de magnetómetro a equidistancias de medio metro. La Cruz del Negro. Mayo, 1997. (Terra Nova).

En la prospección magnética, el sensor capta una señal de la intensidad en el magnetismo del suelo y la registra digitalmente. La realización de lecturas equidistantes proporciona un mapa de estas intensidades que refleja la aparición de anomalías en determinadas zonas del terreno debidas tanto al magnetismo termoremanente como a remociones del suelo.

Estas anomalías suponen por tanto la presencia de elementos sepultados con un magnetismo diferente al del suelo circundante y que pueden corresponder a la localización de arcilla cocida; de hogares u hornos de cerámica; de objetos de hierro; de hoyos y de zanjas. El resultado es el registro de estas intensidades energéticas en forma de imagen con unos valores que han de localizarse exactamente para su comprobación empírica. 

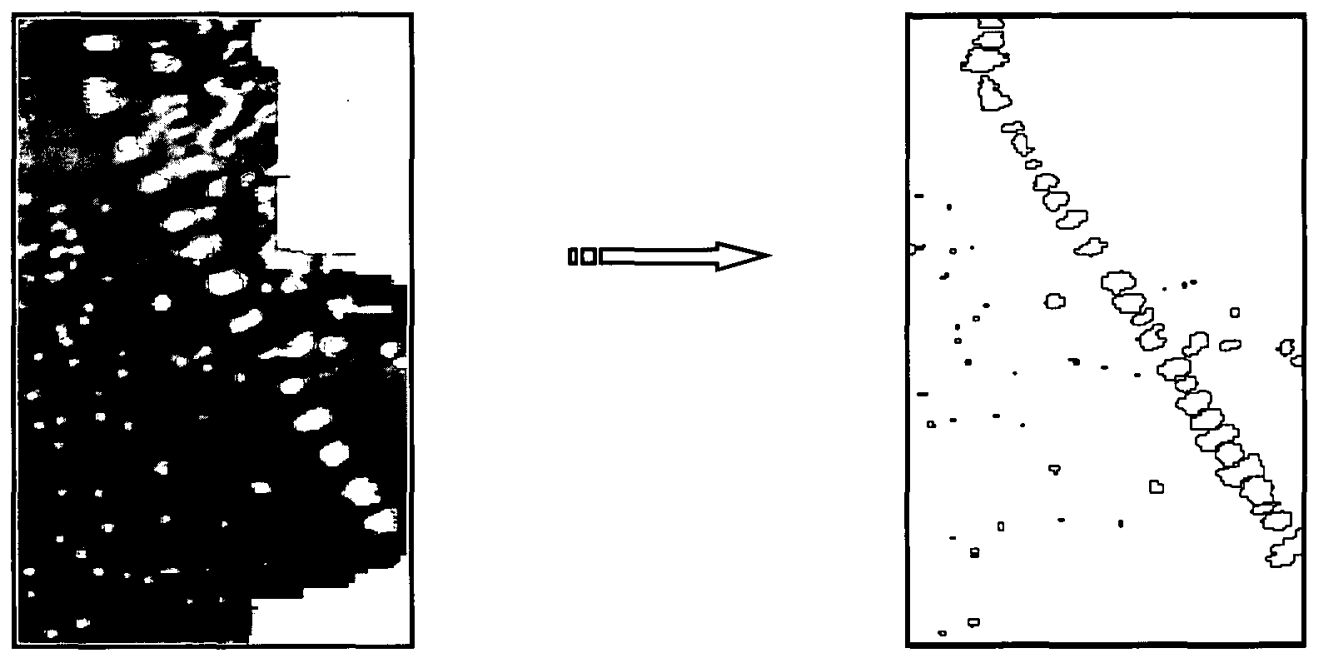

Lám II.- Imagen bidimensional obtenida del registro de intensidades en niveles digitales (ND; escala de grises, 0 a 255 valores) (Terra Nova) y conversión a formato vectorial (H. Márquez \& P. Pérez Quesada).

En definitiva, las imágenes de que disponemos (fotografía aérea e imagen de anomalías) suponen un registro espacial de distribución regular en forma de malla y en el que cada celda o píxel acumula un valor energético (niveles de grises o niveles digitales) de diferente interpretación. En el primer caso nos servirán para la comprobación planimétrica y en el segundo para la detección de posibles estructuras aún no excavadas.

Por otra parte, de la misma toma de datos se derivan implicaciones geométricas importantes y que diferencian a las dos imágenes de cara a su georreferenciación. La imagen de anomalías reproduce formas, áreas, distancias y direcciones con cierta fidelidad (sin considerar las deformaciones que provienen del mismo fenómeno magnético) al haber sido tomados sus datos directamente de la superficie del sitio a una escala determinada; por tanto su transformación a coordenadas reales sólo la hemos realizado por medio del escalado, la traslación y el giro ${ }^{6}$. Por el contrario, el cúmulo de deformaciones a que está sujeta una fotografía aérea impide un ejercicio similar y habrá que recurrir a algoritmos de georreferenciación más complicados que, además del escalado, la traslación y el giro, corrijan sus distorsiones geométricas.

Será necesario pues introducir unas breves nociones sobre los principios teóricos de estas transformaciones geométricas, operaciones cuyo objetivo es pasar las coordenadas de un sistema de referencia (en nuestro caso expresadas en unidades de digitalización o pulgadas) a otro (U.T.M., expresado en metros).

En primer lugar hay que señalar que existen dos variantes en la forma de geocodificar la localización espacial en ejes de coordenadas: la continua y la discreta. Para entender esta distinción baste decir que la continua es la típica representación vectorial de elementos espaciales mediante puntos, líneas y polígonos

6. En realidad se trata de una transformación de un sistema de coordenadas planas establecido libremente por nosotros a un sistema de coordenadas planas de carácter general y prefijadas, como es la U.T.M, del que hay que tener presente las distorsiones y errores por su carácter de proyección de la esfera terrestre a un plano; sin embargo, la adaptación proyectiva no es necesaria a la escala que estamos trabajando. 
(es el caso de nuestra planimetría de campo digitalizada) y la discreta se corresponde con la representación de imágenes mediante píxeles (fotografía escaneada e imagen de anomalías).

En cualquier caso, los procesos de transformación cuentan con unos pasos similares de partida, los cálculos de las funciones de transformación, pero se complican en la variante discreta al tener que asignar los niveles digitales (ND) originales a la posición corregida.

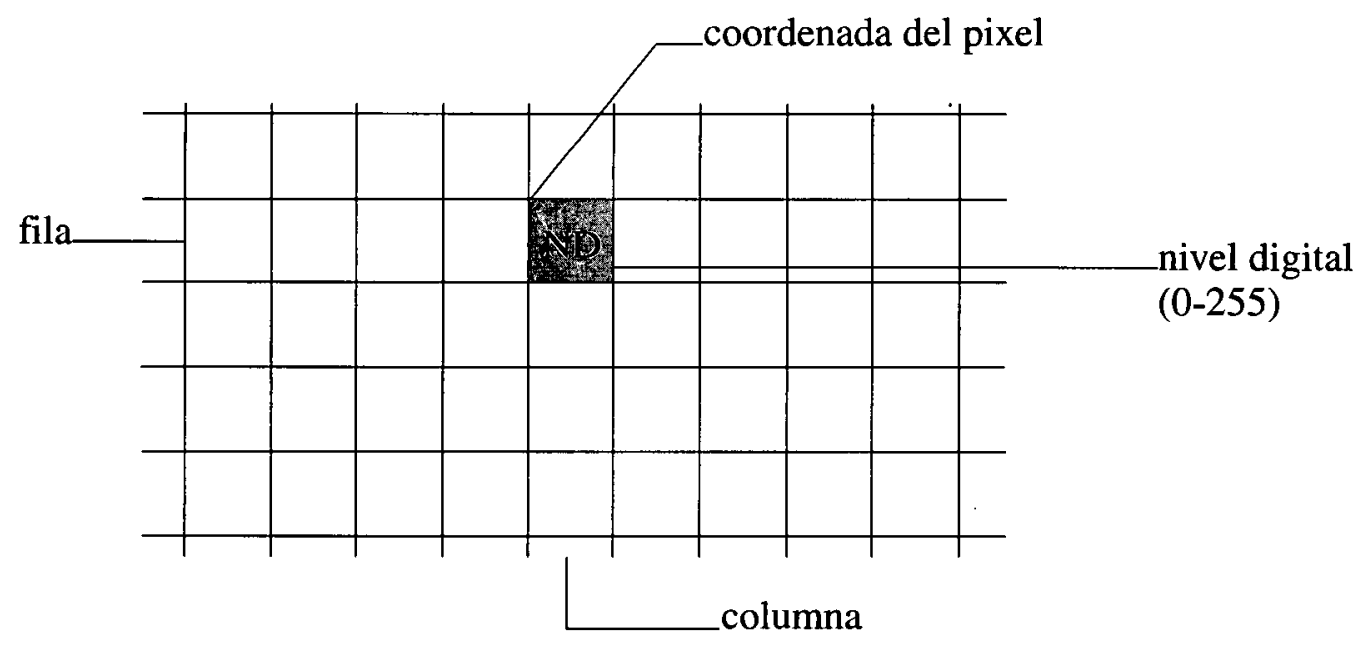

Fig 2.- Componentes de una imagen digital.

Las funciones de transformación son unas fórmulas algebraicas que a cada par de coordenadas del sistema de referencia original hace corresponder otro en el mapa de referencia final. Estas fórmulas se expresan como un sistema de ecuaciones cuyos coeficientes son calculados a partir de unos puntos de control de coordenadas conocidas para ambos sistemas de referencia. La función encontrada será aquella que satisfaga al máximo las posiciones de todos los puntos de control de tal modo que los cuadrados de las desviaciones sean mínimos ${ }^{7}$. Una vez obtenidos los coeficientes la función se itera para todas las coordenadas que han de ser transformadas. Finalmente, para tener una estimación del grado de ajuste de los valores estimados y los observados normalmente se procede al cálculo del error cuadrático medio (RMS -del inglés Root Mean Square) cuyo valor debe quedar por debajo de un umbral fijado por el analista.

Comúnmente se emplean funciones polinómicas para definir el sistema de ecuaciones, determinando el grado del polinomio, el tipo de transformación (traslación, rotación, escala y correcciones residuales

7. El método más habitual para obtener los coeficientes de las funciones de transformación es aplicar un ajuste por mínimos cuadrados, con operaciones de cálculo idénticas a las que requiere una regresión múltiple convencional (Jensen 1996) 
aleatorias) y el número de puntos de control necesario. El caso más sencillo es el de la transformación afín, que opera sin modificar la rectitud ni el paralelismo, y si un punto divide a un segmento en una razón dada seguirá dividiéndolo en la misma razón. En transformaciones de segundo grado o superior se introducen modificaciones de curvatura, siendo tanto más acusada la deformación de las rectas cuanto mayor es el grado del polinomio.

A partir de estas nociones se puede entender que las transformaciones afines (lineales) son las más apropiadas para la representación en coordenadas reales de los datos tomados directamente sobre el terreno; es decir, para la planimetría de campo y para la imagen de la prospección magnética. Por otra parte, como suele recomendarse en los manuales al uso, las transformaciones no lineales son las usadas para correcciones geométricas de fotografías espaciales o aéreas, como es el caso de nuestra imagen del sitio, ya que proporcionan la posibilidad de corregir sus deformaciones geométricas.

Para la variante de geocodificación continua basta implementar las funciones señaladas para obtener el producto deseado; sin embargo, para la discreta resulta necesario trasvasar los ND originales a la posición obtenida, lo que supone un segundo paso una vez transformada la imagen original. El problema que surge es que las coordenadas obtenidas de la transformación, en números reales, no coincidirán con la situación de las celdillas de la imagen, que corresponden a números enteros de columnas y filas. Esto se resuelve mediante unos algoritmos de interpolación de los ND a partir de los originales, proceso que es conocido

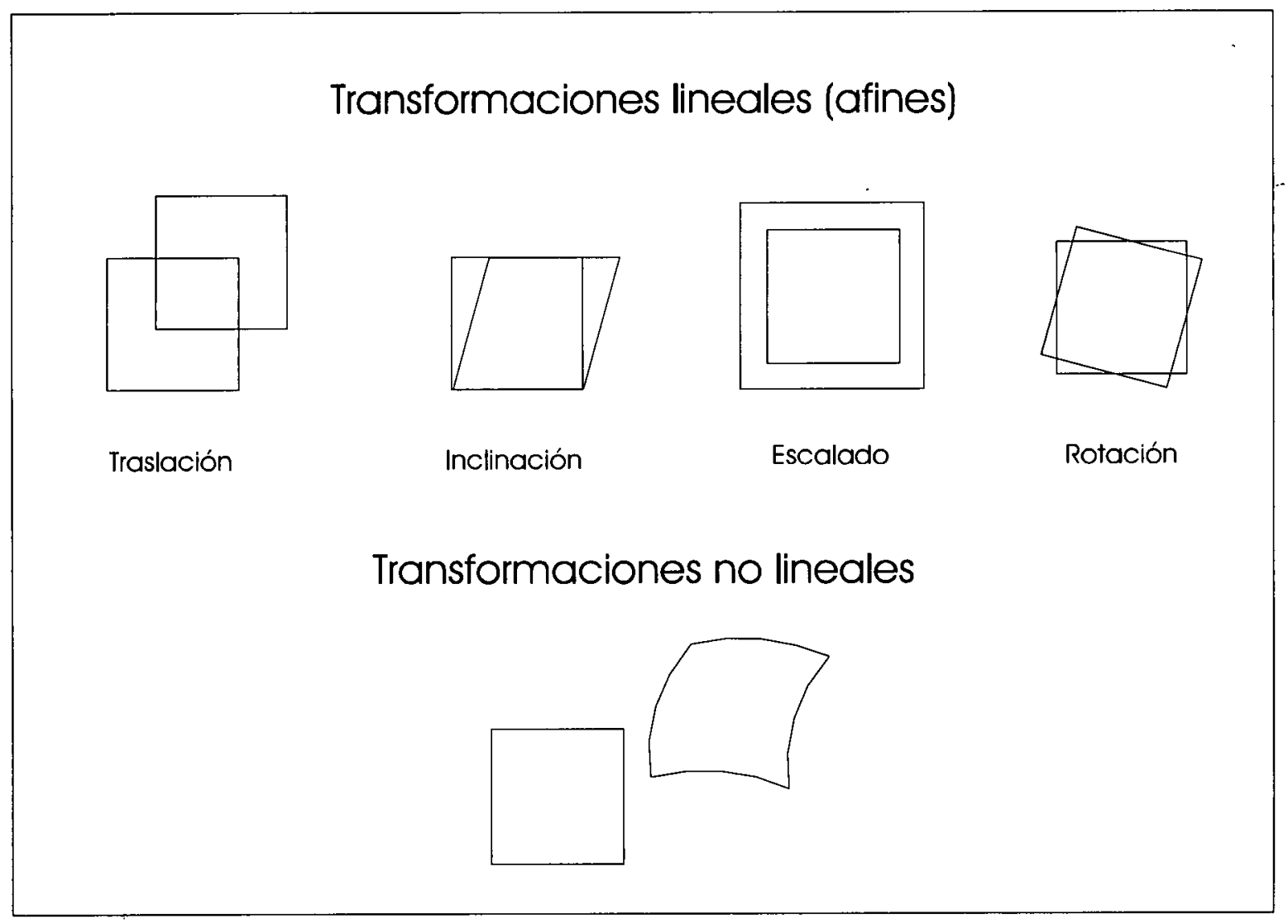

Fig 3.- Ejemplos de transformación geométrica 


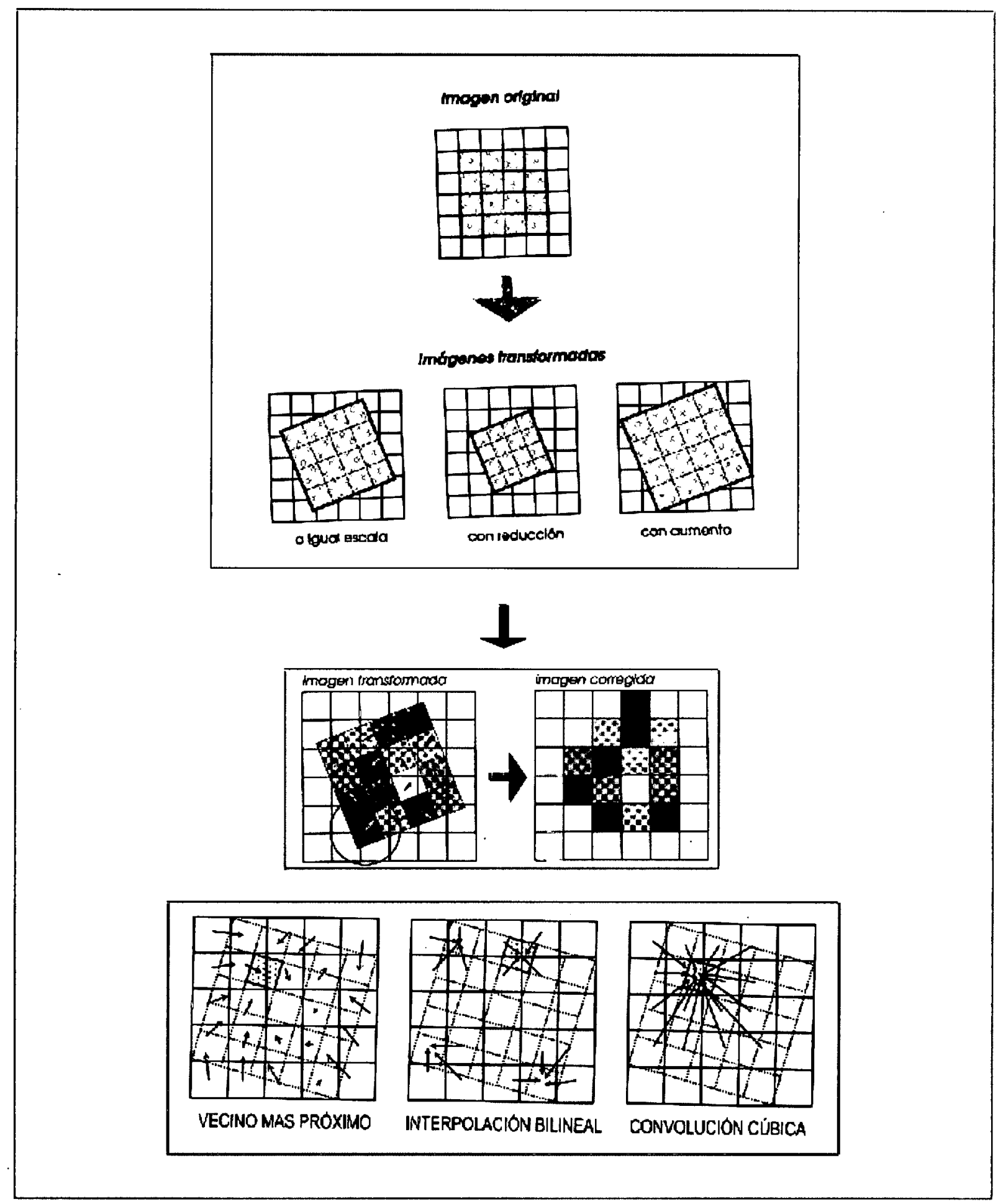

Fig. 4. - Procedimientos de transformación y remuestreo de imágenes digitales (Composición propia a partir de Pinilla 1995 y Chuvieco 1996) 
en el lenguaje de imágenes como remuestreo (Pinilla 1995) ${ }^{8}$. Estos métodos son: 1. vecino más próximo, que sitúa en cada píxel de la imagen corregida el ND del píxel más cercano en la imagen transformada, 2. interpolación bilineal, que promedia los ND de los cuatro píxeles más cercanos en la transformada, ponderándolos con la distancia y 3. convolución cúbica, que considera los 16 píxeles más próximos.

Hasta el momento hemos desarrollado mínimamente los conceptos elementales para la comprensión de los resultados que a continuación se exponen ${ }^{9}$.

\section{Aplicación Práctica. La necrópolis de La Cruz del Negro.}

Para la necrópolis de La Cruz del Negro ya hemos señalado cuales fueron las directrices seguidas en su planimetría. A continuación vamos a explicar los últimos trabajos realizados para la liberación del expediente de urgencia.

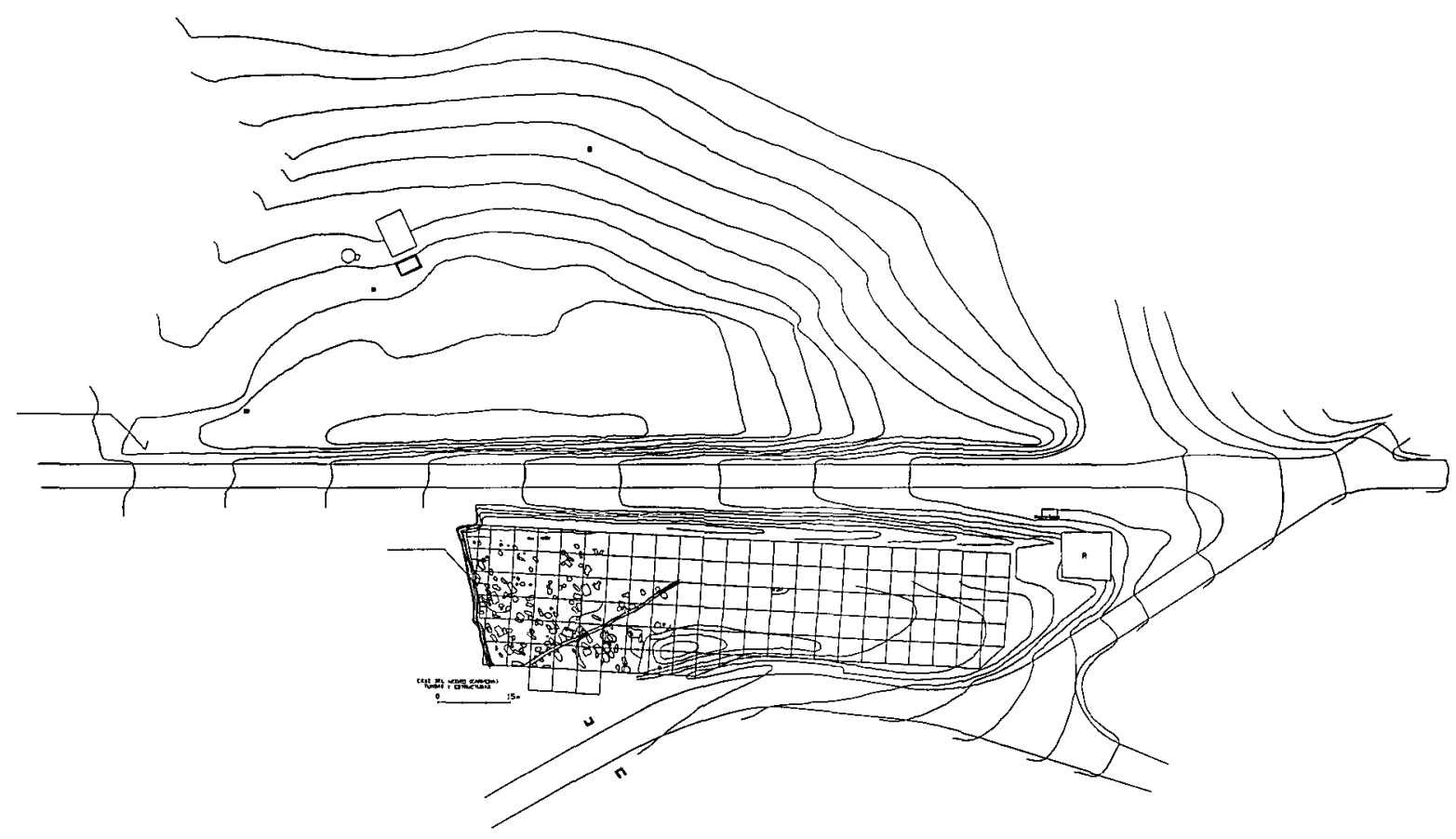

Fig.5.- Planimetría arqueológica de las campañas 1990-1995 ( M C. Rodríguez-Bobada) referenciada sobre el levantamiento topográfico del emplazamiento (TecnoCart). Mayo, 1996 (fuente: Amores y otros 1997). El cuadriculado de referencia (cuadrículas de $5 \times 5 \mathrm{~m}$ ) se deriva de la prospección geofísica de PROARSA (cuadrículas de $20 \times 20 \mathrm{~m}$ ).

8. En adelante se distinguirá entre imagen transformada, resultante de la transformación geométrica por las funciones de ajuste, e imagen corregida, producto del remuestreo de la imagen transformada.

9. El desarrollo de los conceptos aquí esbozados es importante para comprender el grado de tolerancia de nuestras correcciones planimétricas y para poder usar un lenguaje técnico incomprensible sin estas matizaciones teóricas. Tanto de las transformaciones geométricas como de las correcciones de imágenes puede encontrarse una mayor profundidad en la bibliografía que se cita. 
En las excavaciones realizadas el registro siguió usos estandarizados, la escala 1:20 y la elección del sistema de ejes o de cuadrículas (de $5 \times 5 \mathrm{~m}$. y subdivisiones menores de $2.5 \times 2.5 \mathrm{~m}$.) para referir espacialmente los hallazgos. Por tanto se trataba de un registro extremadamente preciso que en 1995 se decidió incluir en el levantamiento topográfico encargado a Tecno Cart. Para ello se digitalizaron en formato vectorial (espacio continuo) los contornos de las fosas funerarias excavadas mediante una tableta digitalizadora; la transformación de las unidades digitales obtenidas a las métricas del levantamiento topográfico seguiría en sus cálculos una función afín, utilizándose en esto los puntos de control de las cuadrículas; la referenciación general del cuadrículado se realizó por medio de unos identificadores (dirección de testigos y cortes de 1990, principalmente) que habían sido detectados en el levantamiento topográfico y que indicaban el

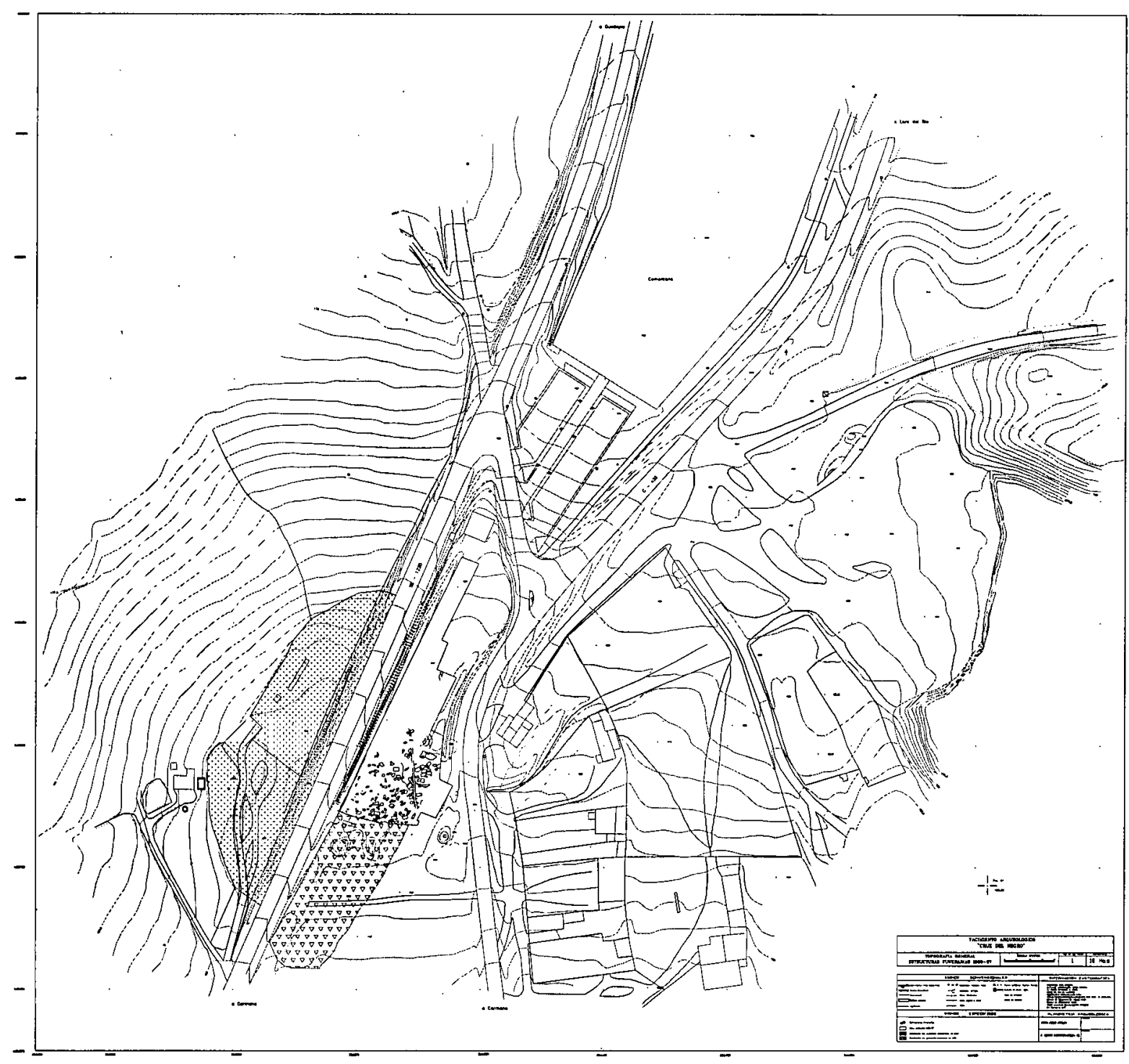

Fig. 6.- Restitución fotogramétrica (con apoyo de campo) en proyección U.T.M. del entorno de la Cruz del Negro (Cartonme) y adaptación de la planimetría arqueológica (1995-1997) al nuevo sistema de referencia (P. Pérez Quesada). Mayo, 1999. Sombreado débil: zona excavada; intenso: zona protegida; triángulos: zona destruida. 
posicionamiento del conjunto excavado. El resultado de todo fue que por primera vez se dispuso de una visión general de las estructuras funerarias y se avanzaba en las posibilidades del análisis espacial a escala de sitio al tener computada la información en unidades reales (metros).

Esta planimetría supuso el punto de partida para los trabajos finales de georeferrenciación. Los pasos sucesivos fueron: la transformación a coordenadas reales de esta planimetría, la inclusión de la planimetría de 1997, la georreferenciación de la fotografía aérea para la comprobación de errores significativos y por último la localización de las anomalías en su posición exacta.

La transformación de la planimetría a coordenadas reales se hizo mediante transformación lineal, de manera que se mantuviese la semejanza. El levantamiento cartográfico de Cartonme proporcionaba puntos de control reconocibles en la planimetría de TecnoCart, con lo que sólo se necesitaron tres puntos de control para desplazar, escalar y girar toda la planimetría de campo hacia coordenadas reales (U.T.M.). El mismo proceso se siguió para la planimetría de 1997, que a diferencia de las anteriores campañas se escaneó y digitalizó en formato vectorial directamente en pantalla.

La identificación de elementos en la cartografía de Cartonme permitió un trasvase de la fotografía aérea a coordenadas U.T.M. mediante una transformación no lineal (polinómica de segundo grado) y con un remuestreo de niveles digitales por el algoritmo del vecino más próximo. Concretamente se utilizaron doce puntos de fácil reconocimiento en la imagen y de coordenadas precisas en la restitución cartográfica. El error cuadrático medio (RMS) era lo suficientemente aceptable (inferior a los cincuenta centímetros) como para comprobar sobre ella la validez de la planimetría de campo restituida.

La comprobación de los resultados de campo fue ciertamente satisfactoria y tan sólo para la campaña de 1990 hubo que hacer un desplazamiento general de la planimetría, (medio metro en dirección sur siguiendo los ejes de la cuadrícula); a esto hay que unir el hecho de que algunas estructuras aisladas (de todas las campañas excepto la de 1997, no registrada en la toma fotográfica) se encontrasen mal localizadas por errores indeterminados (dibujo de campo, digitalización, tratamiento de datos...) y tuvieran que ser desplazadas.

Hay que tener presente que la imagen está distorsionada y supone una referencia relativa para la corrección de errores, pero no podemos entenderla como una referencia absoluta. En realidad el producto digital obtenido no puede considerarse una ortoimagen ${ }^{10}$ ya que persisten las deformaciones debidas al relieve; ahora bien, al ser muy pequeñas las diferencias de altitud dentro de la escena el resultado dista muy poco del deseado. Lo es cierto es que las modificaciones planimétricas que se realicen siempre han de hacerse tras una interpretación minuciosa de referencias claras, como estructuras arquitectónicas del entorno, perfiles de excavación, etc., que hayan tenido puntos de apoyo cartográfico. En el caso que nos ocupa tan sólo se han modificado aquellas localizaciones de fosas que coincidan con la imagen tras su desplazamiento en unidades de medio metro y en las direcciones del cuadriculado.

La imagen de la prospección magnética ha recibido un tratamiento diferente en su georeferenciación con el objetivo de poder visualizarla conjuntamente con la imagen aérea y la planimetría. En primer lugar se han seleccionado aquellos píxeles con ND más elevados (anomalías más fuertes) y se han representado en formato vectorial con tres niveles de intensidad. La transformación a coordenadas reales se ha realizado finalmente mediante una función afín, a partir de la comprobación de los puntos de control de campo establecidos por Terra Nova y revisados por nosotros.

La comprobación empírica de estas anomalías ha dado resultados congruentes con la intensidad de las mismas. Las anomalías más intensas respondían a varias circunstancias; por una parte, la franja continua de anomalías ya sabíamos que respondía a la línea de Telefónica que cruza el sitio. Del resto de anomalías se desconocía su origen pero fueron confirmadas por diferentes respuestas: en dos casos se trataba de barras de hierro, una clavada y la otra en el interior de una tumba excavada en 1990. Otras anomalías en el sector excavado

10. Fotografía transformada a proyección ortogonal, con lo que se corrigen las distorsiones ocasionadas por el efecto que tiene el relieve del terreno en la proyección cónica de los haces perspectivos (Mena 1992). 


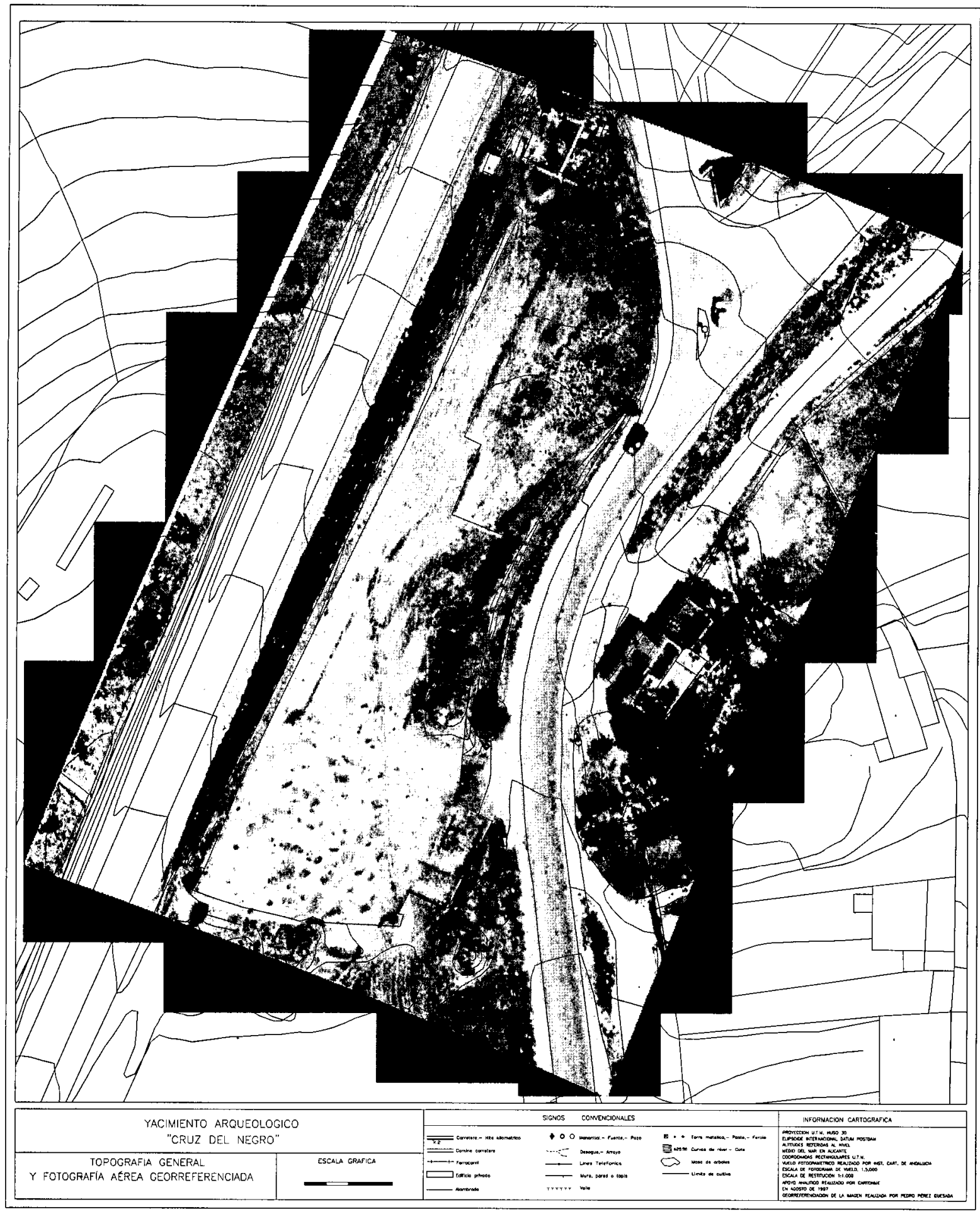

Lám III.- Fotografía aérea del yacimiento en marzo de 1995 georreferenciada en coordenadas U.T.M. (P. Pérez Quesada). Mayo, 1999. 


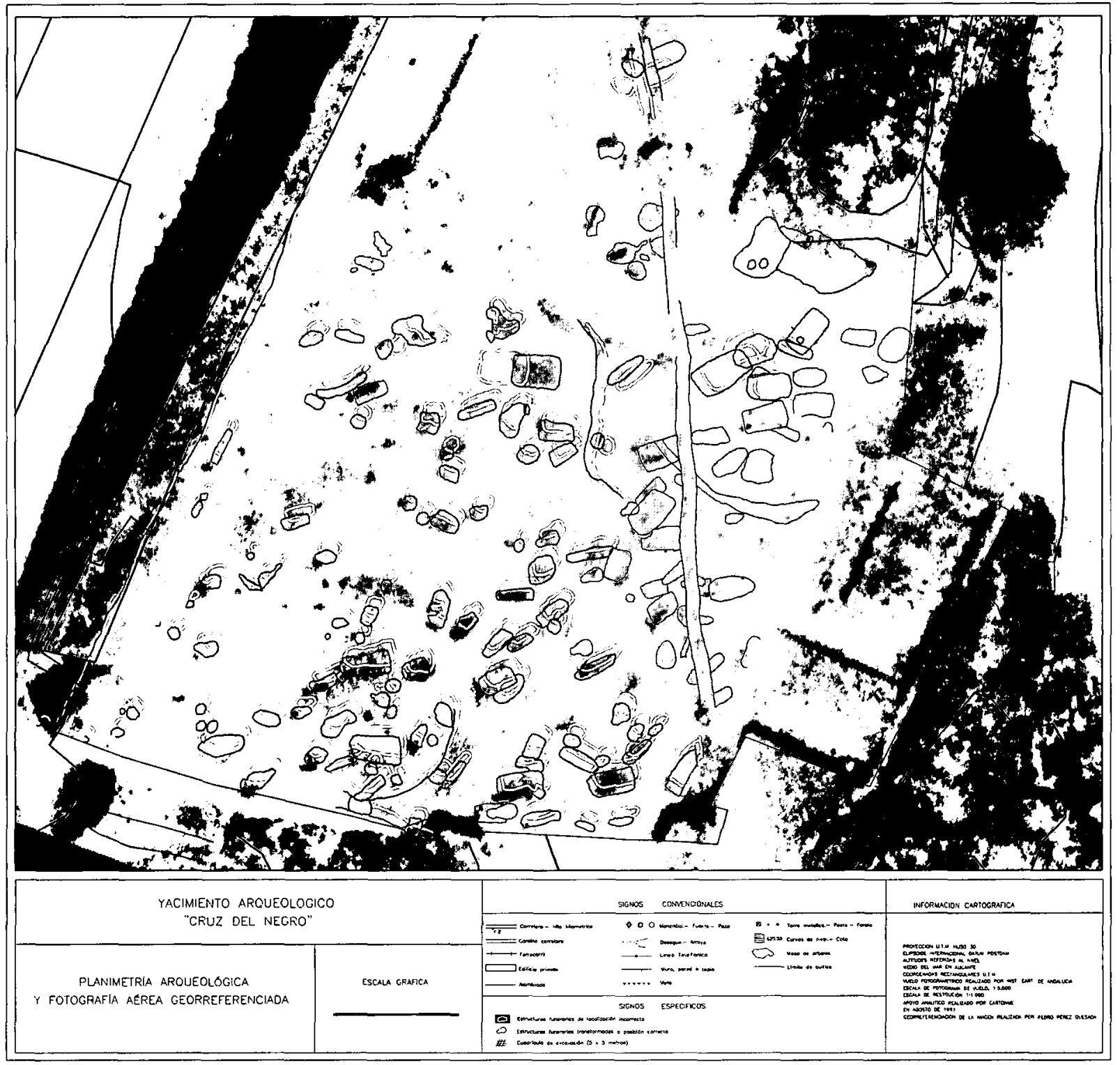

Lám. IV.- Transformaciones de la planimetría arqueológica a partir de la fotografía aérea georreferenciada (P. Pérez Quesada)

en esa fecha respondían también a restos metálicos: puntillas para la sujeción de cuerdas de cuadrícula, claramente alineadas y que se manifestaban en la imagen con una intensidad media o débil (según su tamaño).

Una serie de anomalías de intensidad media en la zona Oeste de 1990 reveló restos de zanjas de las excavaciones del siglo pasado, confirmadas por la presencia de cerámica moderna y restos de carbonilla del ferrocarril, y que demostraron la arbitrariedad en el seguimiento metodológico de entonces (zanjas de recorrido aleatorio). Los resultados más importantes fueron confirmados por la campaña de excavación de 1997 en el sector medio Este, el único no excavado antes de la prospección. Las anomalías más intensas respondieron aquí a la presencia de tres estructuras funerarias con importantes restos de carbón vegetal, 


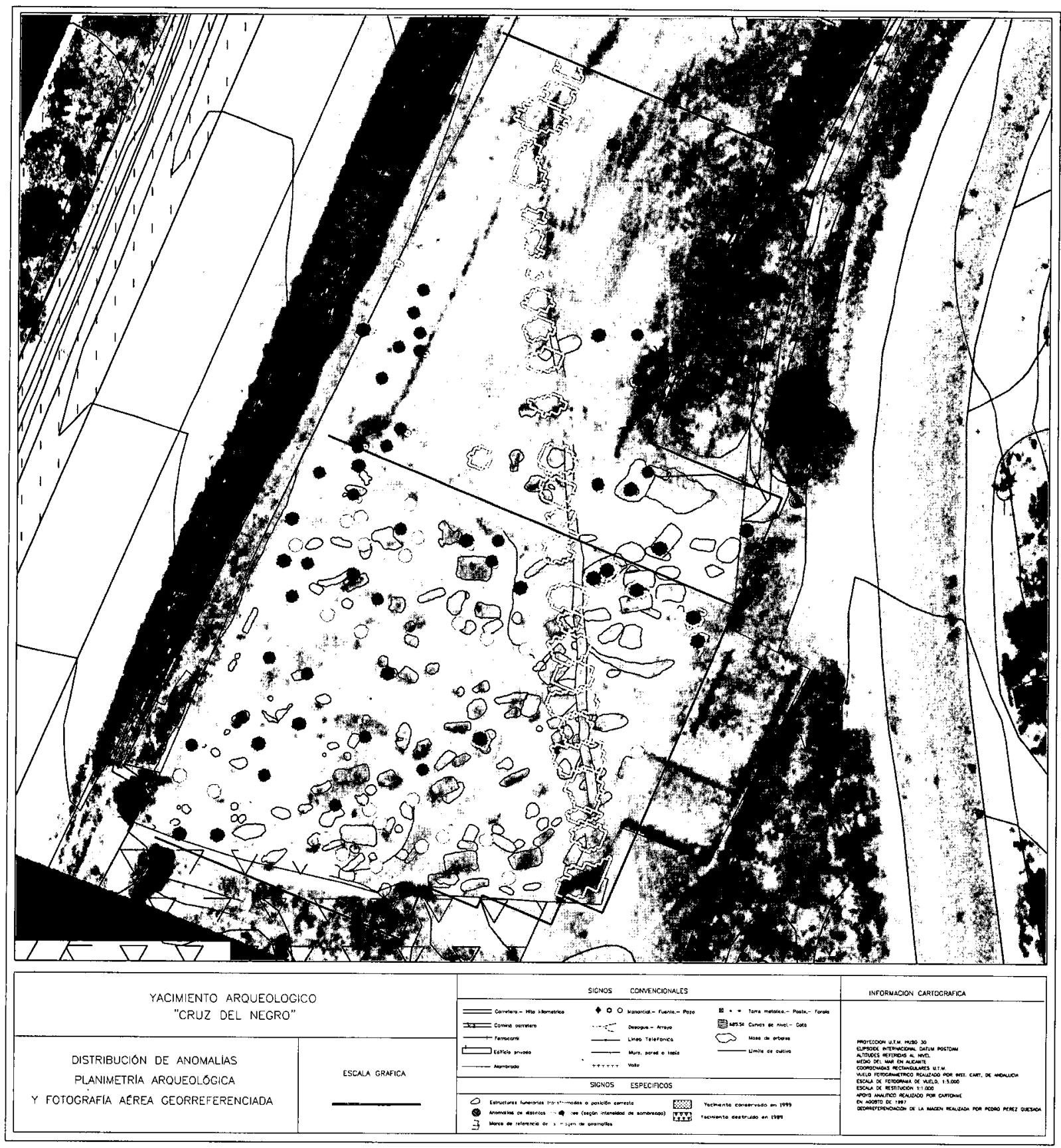

Lám. V.- Resultados de prospección magnética georreferenciados (P. Pérez Quesada)

producto del ritual incineratorio. El resto de anomalías se debían a la acumulación de desechos en pequeñas terreras de excavaciones precedentes.

Sobre su localización precisa hay que señalar que depende en cierta medida de la respuesta captada por el sensor, que ofrece un desplazamiento teórico de unos $40 \mathrm{~cm}$ desde su origen (objeto emisor) y en sentido Suroeste; en realidad se da un acercamiento bastante aceptable, pero no hemos podido confirmar exactamente la orientación que hipotéticamente se esperaba por parte de los técnicos. 
Con la comprobación de la prospección magnética se llegaba al final del expediente administrativo de urgencia ${ }^{11}$ y se podía presentar un registro planimétrico completo que ha sido utilizado en el informe para delimitar el sector fértil de la necrópolis aún conservada a los efectos de su protección.

Con estos trabajos creemos que se han avanzado nuevas formas de control en el registro espacial de una excavación ejecutada en campañas sucesivas por diferentes equipos y planimetrías acumuladas producidas de acuerdo con metodologías tradicionales con carencias de precisión contextual. El control gráfico expuesto de la planimetría de la necrópolis permitirá el desarrollo de interpretaciones a nivel micro más fiables de lo que hubiera sido posible con el estado de la planimetría resultante de las intervenciones. Téngase en cuenta que las siluetas de estructuras funerarias presentes en la planimetría que se ofrece no corresponden a la totalidad de las excavadas. Debido a la destrucción parcial de la necrópolis en un sector concreto se registraron huellas y diferentes evidencias que corresponden a estructuras funerarias parcialmente destruidas pero que están siendo rescatadas para su inclusión en la planimetría de acuerdo con el proceso de digestión e interpretación de la información. Igualmente hay otros tipos de evidencias que no se presentaban en estructuras excavadas en la terraza pero que forman parte de la información contextual de la necrópolis. Todo ello pone de relieve la necesidad de disponer de un registro planimétrico preciso con objeto de interpretar asociaciones y relaciones funerarias en el sitio arqueológico.

\section{BIBLIOGRAFÍA}

AMORES, F.; AUBET, M ${ }^{a}$ E.; GIL, M S. Y PUYA, M. (1997ª): "Cambio Cultural y Mecanismos de Transformación de la Sociedad Tartésica durante el Bronce Final y el Orientalizante en el Bajo Guadalquivir: el caso de Carmona, Setefilla y el Carambolo. $1^{\text {a }}$ campaña, 1991: documentación gráfica." Anuario Arqueológico de Andalucía 1993, II: 149-153. Sevilla.

__ (1997b): "Cambio Cultural y Mecanismos de Transformación de la Sociedad Tartésica durante el Bronce Final y el Orientalizante en el Bajo Guadalquivir: el caso de Carmona, Setefilla y el Carambolo. $2^{\mathrm{a}}$ campaña: excavación sistemática en la necrópolis de la Cruz del Negro" Anuario Arqueológico de Andalucía 1993, II: 154-158. Sevilla.

BONSOR, J. (1997): [1899] Las Colonias Agricolas Prerromanas del Valle del Guadalquivir. Traducción del francés y estudio preliminar de Jorge Maier. Gráficas Sol. Écija .

BOSQUE SENDRA, J. (1997): Sistemas de Información Geográfica. $2^{\mathrm{a}}$ ed. Ed. Rialp., Madrid.

BURROUGH,P.A. (1987): Principles of Geographical Information Systems for Land Resourses Assessment, $2^{\text {nd }}$. ed., Oxford University Press, New York.

CHUVIECO SALINERO, E. (1996): Fundamentos de Teledetección Espacial, $3^{\circ}$ ed. Ed. Rialp,. Madrid. DOMINGO AJENJO, A. (1994): Tratamiento Digital de Imágenes. Ed. Anaya. Madrid.

ESRI (Environmental Systems Research Institute, Inc.) (1992): ARC Command References. ARC/INFO User's Guide. Ed. ESRI. Redlands.

GIL, Ma S.; PUYA, M.; MAIER, J.; VIÑUALES, O.; LUQUE, J.M.; FRANCO, C. Y HUECAS, J.M. (1991): "Informe preliminar sobre el resultado de la excavación de emergencia de la necrópolis tartésica de la Cruz del Negro (Carmona, Sevilla). Anuario Arqueologico de Andalucía. 1989. III: 611-612. Sevilla. JENSEN, J.R., (1996): Introductory Digital Image Processing. A Remote Sensing Perspective, $2^{\mathrm{a}}$ ed., Prentice Hall, Upper Saddle River N.J.

MENA BERRIOS, J. (1992): Cartografia Digital. Desarrollo de software interno. Ed. Ra-ma. Madrid. PINILLA RUIZ, C. (1995): Elementos de Teledetección. Ed. Ra-ma, Madrid.

11. La certeza descansa en este caso en el tipo conocimiento del tipo de estructuras funerarias de la Cruz del Negro ya que se pudo comprobar que los sectores sistemáticamente excavados (1993 y 1995) no ofrecían anomalía magnética alguna coincidiendo ambas metodologías en el diagnóstico de "agotados", la manual de excavación intensiva y la geofísica. 